\title{
Life-threatening or organ-impairing Henoch-Schönlein purpura: plasmapheresis may save lives and limit organ damage
}

\author{
Donghi, D ; Schanz, U ; Sahrbacher, U ; Recher, M ; Trüeb, R M ; French, L E ; Hafner, J
}

\begin{abstract}
Adult-onset Henoch-Schonlein purpura (HSP) tends to become chronic-relapsing, yet rarely leads to organ impairment, e.g. due to chronic glomerulonephritis. Bed rest, compression and nonsteroidal anti-inflammatory drugs are usually sufficient to control the active phases. We report 2 cases of adult HSP with an unusually severe evolution. One patient required intensive-care treatment for hypovolemic shock caused by hemorrhagic pancolitis; the other had progressive and extremely extensive vasculitic leg ulcers. Both were refractory to common immunosuppression with systemic corticosteroids (oral and pulse) and additive steroid-sparing immunosuppressive drugs. Only after the introduction of plasmapheresis did both patients show a dramatic improvement in the disease, with rapid and almost complete healing. Plasmapheresis is a rarely used therapeutic tool in the treatment of severe HSP, but the growing literature on its highly beneficial effect underlines its potential usefulness.
\end{abstract}

DOI: https://doi.org/10.1159/000223237

Posted at the Zurich Open Repository and Archive, University of Zurich

ZORA URL: https://doi.org/10.5167/uzh-27957

Journal Article

Published Version

Originally published at:

Donghi, D; Schanz, U; Sahrbacher, U; Recher, M; Trüeb, R M; French, L E; Hafner, J (2009). Lifethreatening or organ-impairing Henoch-Schönlein purpura: plasmapheresis may save lives and limit organ damage. Dermatology, 219(2):167-170.

DOI: https://doi.org/10.1159/000223237 


\title{
Life-Threatening or Organ-Impairing Henoch-Schönlein Purpura: Plasmapheresis May Save Lives and Limit Organ Damage
}

\author{
Davide Donghi $^{\mathrm{a}} \quad$ Urs Schanz $^{\mathrm{b}} \quad$ Ulrike Sahrbacher ${ }^{c} \quad$ Mike Recher $^{c}$ Ralph M. Trüeb ${ }^{\mathrm{a}}$ \\ Beat Müllhaupt ${ }^{d}$ Lars E. French ${ }^{a}$ Jürg Hafner ${ }^{a}$ \\ Departments of a Dermatology, ${ }^{b}$ Hematology, ${ }^{c}$ Clinical Immunology and ${ }^{\mathrm{d}}$ Gastroenterology and Hepatology, \\ University Hospital of Zürich, Zürich, Switzerland
}

\section{Key Words}

Henoch-Schönlein purpura • Pancolitis · Plasmapheresis • Immunosuppression •

Leg ulcers, extensive

\begin{abstract}
Adult-onset Henoch-Schönlein purpura (HSP) tends to become chronic-relapsing, yet rarely leads to organ impairment, e.g. due to chronic glomerulonephritis. Bed rest, compression and nonsteroidal anti-inflammatory drugs are usually sufficient to control the active phases. We report 2 cases of adult HSP with an unusually severe evolution. One patient required intensive-care treatment for hypovolemic shock caused by hemorrhagic pancolitis; the other had progressive and extremely extensive vasculitic leg ulcers. Both were refractory to common immunosuppression with systemic corticosteroids (oral and pulse) and additive steroid-sparing immunosuppressive drugs. Only after the introduction of plasmapheresis did both patients show a dramatic improvement in the disease, with rapid and almost complete healing. Plasmapheresis is a rarely used therapeutic tool in the treatment of severe HSP, but the growing literature on its highly beneficial effect underlines its potential usefulness.
\end{abstract}

Copyright $\odot 2009$ S. Karger AG, Basel

\section{Introduction}

Henoch-Schönlein purpura (HSP) is a systemic small vessel leucocytoclastic vasculitis characterized by vascular deposition of IgA immune complexes. It mostly affects children, being the most common vasculitis of childhood with $50 \%$ of all cases occurring before the age of 5 years [1]. The exact pathogenesis of serum IgA immune-complex-level dysregulation remains unknown; however, group A streptococcal tonsillitis/pharyngitis and unspecific upper airway infections are the most common triggering factors [2]. HSP has also been reported to appear in association with malignancy, mostly with solid tumors but also in the setting of plasma cell dyscrasias like multiple myeloma [37], and also as a first manifestation of myeloma [5-7]. The disease typically presents with a classic palpable purpura, mostly involving the lower extremities, due to erythrocyte extravasation into the skin. Polyarthralgia, usually of the knees and ankles, is present in more than $80 \%$ of patients [1]. More than half of the patients have colicky abdominal pain, which can be associated with mild bloody diarrhea. The most feared feature of HSP is glomerulonephritis (IgA nephropathy), occurring in 40$50 \%$ of patients and manifesting in most cases as proteinuria, microhematuria and erythrocyte casts. Nephropathy represents the most common cause of morbidity and death related to HSP, with $12-19 \%$ of children progressing to transient renal failure and up to $3 \%$ to chronic end-stage renal disease $[8,9]$. Other rare complications include central nervous system vasculitis, orchitis, and cardiac and ophthalmological involvement [10].

HSP usually has a spontaneous selflimiting favorable evolution, with up to $95 \%$ of affected patients showing a complete remission within a few weeks. The overall prognosis is excellent, even with one third to one half of patients having 1 or more recurrences of symptoms (usually within 6 weeks, but also as late as 3-7 years) afterwards [11].

Clinical manifestations in adult-onset HSP tend to be more pronounced and recurrences are more frequent. In rare cases, HSP can become organ-compromising or even life-threatening. The 2 reported cases are good examples of refractory or even life-threatening HSP, for whom systemic corticosteroids, both oral and intravenous pulse, and steroid-sparing agents did not stabilize the disease. Eventually, plasmapheresis led to a rapid and long-lasting remission in both patients.

\section{KARGER}

Fax +4161306 1234 E-Mail karger@karger.ch www.karger.com
(C) 2009 S. Karger AG, Basel

$1018-8665 / 09 / 2192-0167 \$ 26.00 / 0$

Accessible online at:

www.karger.com/drm
Dr. med. Davide Donghi

Dermatologische Klinik, Universitätsspital Zürich

Gloriastrasse 31

CH-8091 Zürich (Switzerland)

Tel. +41 4425526 89, Fax +41 4425592 56, E-Mail davide.donghi@usz.ch 


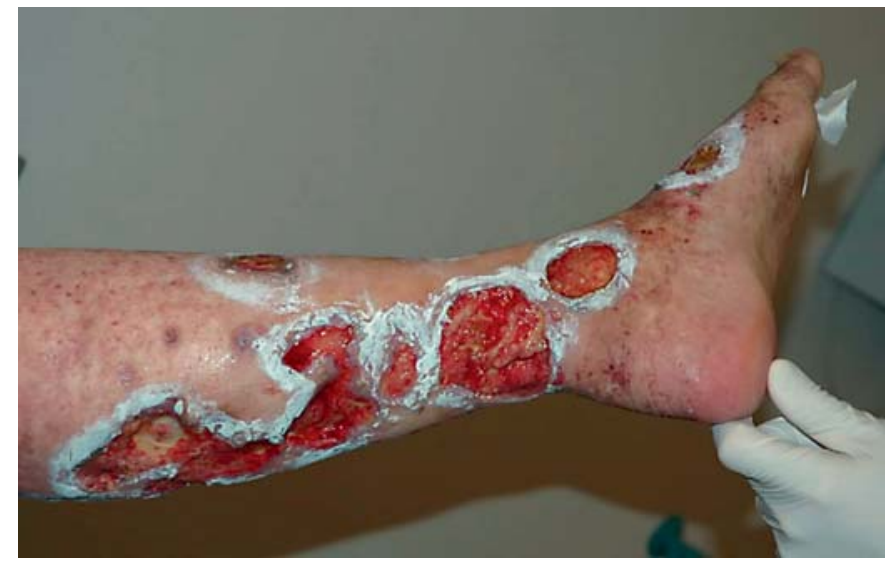

Fig. 1. Patient 1: presentation at first dermatological evaluation, with deep and painful polycyclic skin ulcers over the whole circumference and length of the left leg.

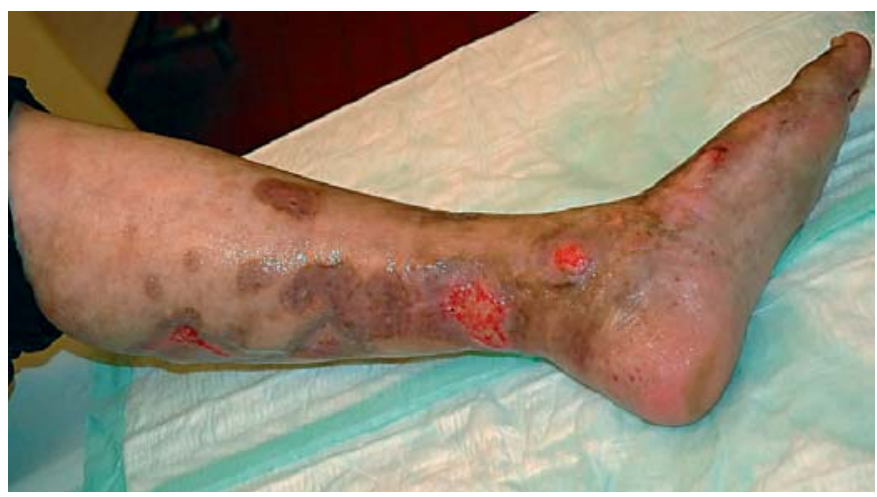

Fig. 2. Patient 1: abundant granulation and re-epithelization in all wounds after 5 plasma exchange sessions.

\section{Case Reports}

\section{Patient 1}

A 44-year-old woman first presented in August 2006 with classical palpable purpura involving her distal legs and arms. Two months later she complained of diffuse and painful joint swelling of her knees, ankles, elbows, and wrists. In December 2006, new crops of palpable purpura started to appear around both ankles. The skin lesions were highly exudative, leading to pustulation and rapid formation of deep and painful polycyclic skin ulcers that continued to extend over the whole circumference and length of legs (fig. 1).

Skin biopsies showed small vessel vasculitis with vascular IgA deposits on direct immunofluorescence, with no significant histological signs of thrombosis. Hematology showed normocytic anemia (11.2 g/dl) and leukocytosis (10.3 g/l with normal differentiation). Urine analysis evidenced light hematuria but no proteinuria, and creatinine clearance was in the normal range. An elevated IgA level was found on immunoserology, and protein electrophoresis detected a monoclonal IgA gammopathy. The cryoglobulin test was negative. A diagnosis of HSP in the presence of monoclonal IgA gammopathy in the setting of a plasma cell dyscrasia (hematologically at the current moment, no further specification), without renal function impairment, was made.

In May 2007, corticosteroid-based immunosuppression was started with oral prednisone $1 \mathrm{mg} / \mathrm{kg} /$ day, together with azathioprine $1.5 \mathrm{mg} / \mathrm{kg} /$ day as the steroidsparing agent. The skin ulcerations continued to extend under this well-controlled immunosuppression. Intravenous methylprednisolone pulse therapy with $1.0 \mathrm{~g}$ i.v. methylprednisolone on the 3 following days, over 3 consecutive months (November 2007 to January 2008) did not show any positive effect either. Meanwhile, the skin lesions had become debilitating.

In February 2008, plasma exchange therapy (plasmapheresis) was started, and 9 sessions over 15 days were scheduled. Already after 5 sessions, all skin ulcerations showed a dramatic improvement with abundant granulation and rapid re-epithelization from the wound borders (fig. 2). Local wound care was kept simple and comprised exclusively chlorhexidine-embedded fatty gauze. The wounds continued to improve and to heal completely under oral prednisone $(0.4 \mathrm{mg} / \mathrm{kg} /$ day $)$ and azathioprine ( $2 \mathrm{mg} / \mathrm{kg} /$ day). After discontinuation of plasmapheresis, the patient experienced a disease reactivation manifesting as palpable purpura and correlating with recurrent detectable serum paraprotein, which required further plasma exchange sessions. Again, recovery was rapid and complete.

\section{Patient 2}

In August 2007, a 28-year-old woman began to complain of swollen ankle joints and arthralgia, and 2 days later showed palpable purpuric skin lesions on both legs and thighs. Hematology, C-reactive protein, hepatic and renal serum parameters,

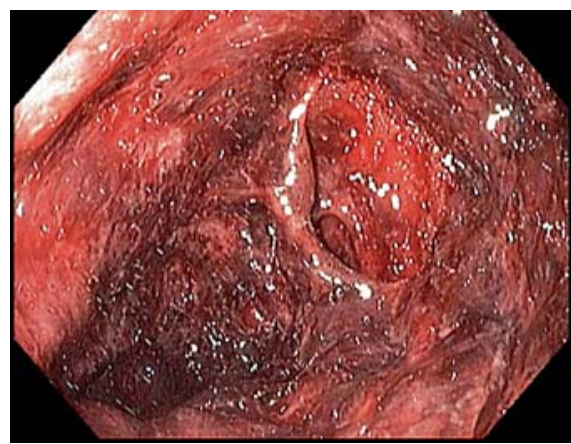

Fig. 3. Patient 2: endoscopic image showing serious hemorrhagic duodenitis.

immunological screening tests, and complete urine analysis were all within normal ranges. Bacteriological culture of a throat swab did not indicate the presence of group A streptococci. After dermatohistopathological confirmation of cutaneous small vessel leukocytoclastic vasculitis with discrete vascular IgA deposits on direct immunofluorescence, a diagnosis of HSP was made.

The course was refractory to oral prednisone at $1 \mathrm{mg} / \mathrm{kg} / \mathrm{day}$, and after 1 week the patient required hospitalization. Treatment was continued on the same dose of prednisone, with bed rest and compression treatment of the legs. The local symptoms continued to be refractory and at the third day of inpatient treatment (15 days after the first consultation) the patient developed acute and profuse hematemesis 
and melena, which led to hypovolemic shock within a few hours. The patient was stabilized and transferred to the intensivecare unit. Gastroscopic images showed a serious hemorrhagic duodenitis (fig. 3), while colonoscopy showed hemorrhagic colitis and terminal ileitis. Histologies provided evidence of exclusively necrotic colon mucosa, but no vasculitic lesions. Abdominal contrast computed tomography showed a pan-enterocolitis, but no evidence of mesenterial artery obstructions.

She was put on intravenous methylprednisolone pulse therapy ( $1.0 \mathrm{~g}$ i.v. methylprednisolone for the 3 following days); however, the pancolitis did not respond sufficiently. After insufficient response under high-dose oral corticosteroids for a further 10 days, the patient was started on plasma exchange treatment (plasmapheresis, 6 plasma exchanges in 10 days), leading to a rapid and long-lasting remission. Oral corticosteroids were continued at $0.25 \mathrm{mg} / \mathrm{kg} /$ day and azathioprine at 2.5 $\mathrm{mg} / \mathrm{kg} /$ day. At present, the patient remains stable.

\section{Discussion}

Plasmapheresis is an extracorporeal blood purification technique that was developed in the late 1970s. Its effect is based on the removal of large molecular weight molecules (e.g. immunoglobulins and immune complexes, paraprotein, undefined autoantibodies, pro-inflammatory cytokines, complement factors, lipoproteins, toxins) from the patient's plasma and substitution with other fluids [12] (fresh frozen plasma, albumin or saline solution, depending on indication and comorbidities). Usually, at least 5 separate exchanges over 7-10 days are required to achieve the removal of $90 \%$ of the total initial immunoglobulin. Due to the highly probable pathogenic role of the monoclonal IgA component in HSP activity in patient 1, we considered plasmapheresis as a very promising solution. The prompt clinical improvement after therapy start confirmed our idea, and was probably due to the elimination of circulating $\operatorname{Ig} \mathrm{A}$.

According to the American Association of Blood Banks [13], plasmapheresis is recognized as standard therapy (category I) for several autoimmune diseases including acute and chronic inflammatory polyradiculoneuropathy, Goodpasture's syndrome, Guillain-Barré syndrome, thrombotic thrombocytopenic purpura and myasthenia gravis. It is also generally accepted in a supportive indication (category II, in association with other systemic treatments) for rapidly progressive glomerulonephritis and hyperviscosity syndrome in myeloma patients.

Dermatological diseases that may benefit from plasmapheresis are listed in category III (relative indications) and comprise systemic lupus erythematosus, refractory pemphigus vulgaris, systemic vasculitis, and severe forms of secondary Raynaud's phenomenon [14].

As an alternative to classic plasmapheresis, the double-filtration technique without plasma replacement has also successfully been used in the treatment of HSP, especially in patients with crescentic glomerulonephritis and acute renal failure [15].

A PubMed search revealed various single case reports regarding plasmapheresis as a sole therapy [16] or in combination with numerous other immunosuppressive drugs [17-22], including oral prednisone, intravenous methylprednisolone, azathioprine and cyclophosphamide. It is of particular interest to note the publication of 2 cases of HSP with cerebral vasculitis [16, $22]$ and 2 cases of severe intestinal involvement $[18,21]$, all responding promptly to plasma exchange. There are also some case series, the largest detailing about 16 children treated between 1988 and 2005 with plasmapheresis monotherapy [23], showing excellent results, as did a smaller series of 9 children [24]. The same clinical improvement was observed in a series of 6 Japanese children who were treated with a combination of plasmapheresis and multiple immunosuppressive drug therapy [8]. The therapy regimens used in the publications listed here were quite heterogeneous and total plasma exchange sessions ranged from 4 to 12 , extending over a time period of 2-6 weeks.

In conclusion, we can add 2 more cases of severe and complicated HSP, refractory to corticosteroids and azathioprine, in whom the introduction of plasmapheresis led to a rapid and long-lasting improvement. The further interest of these cases lies in the life-threatening complications of patient 2, the extremely extensive skin necrosis of the legs in patient 1 , and in the rare setting of HSP in plasma cell dyscrasia with monoclonal IgA gammopathy (patient 1 ), with very few cases having been reported in the literature [3-7]. Plasma exchange rapidly and directly eliminates the circulating $\operatorname{IgA}$ immune complexes. A combination with classical immunosuppression should help to inhibit the ongoing production of immunoglobulin and proinflammatory cytokines, and thus avoid relapses or rebound phenomenon after cessation of the plasma exchange therapy. At present, there are no comparative studies addressing this issue. The higher risk of short-term (infections, gastrointestinal disorders) and long-term (neoplasia, Cushing syndrome) side effects related with prolonged and/or high-dose immunosuppressive drug therapy has to be balanced on an individual basis with the risk of continuing disease activity.
References
1 Roberts PF, Waller TA, Brinker TM, Riffe IZ, Sayre JW, Bratton RL: Henoch-Schönlein purpura: a review article. South Med J 2007; 100:821-824.

2 Saulsbury FT: Epidemiology of HenochSchönlein purpura. Cleve Clin J Med 2002; 69:SII87-SII89.

3 Zurada JM, Ward KM, Grossman ME: Henoch-Schönlein purpura associated with malignancy in adults. J Am Acad Dermatol 2006;55(suppl 5):S65-S70.
4 Dosa S, Cairns SA, Mallick NP, Lawler W, Williams G: Relapsing Henoch-Schönlein syndrome with renal involvement in a patient with an IgA monoclonal gammopathy: a study of the results of immunosuppressant and cytotoxic therapy. Nephron 1980;26: 145-148.

5 Zickerman AM, Allen AC, Talwar V, Olczak SA, Brownlee A, Holland M, Furness PN, Brunskill NJ, Feehally J: IgA myeloma presenting as Henoch-Schönlein purpura with nephritis. Am J Kidney Dis 2000;36:E19. 
6 Van Der Helm-Van Mil AH, Smith AC, Pouria S, Tarelli E, Brunskill NJ, Eikenboom HC: Immunoglobulin A multiple myeloma presenting with Henoch-Schönlein purpura associated with reduced sialylation of IgA1. Br J Haematol 2003;122:915-917.

7 Birchmore D, Sweeney C, Choudhury D, Konwinski MF, Carnevale K, D’Agati V: IgA multiple myeloma presenting as HenochSchönlein purpura/polyarteritis nodosa overlap syndrome. Arthritis Rheum 1996; 39:698-703.

8 Kawasaki Y, Suzuki J, Murai M, Takahashi A, Isome M, Nozawa R, Suzuki S, Suzuki H: Plasmapheresis therapy for rapidly progressive Henoch-Schönlein nephritis. Pediatr Nephrol 2004;19:920-923.

9 Sanders JT, Wyatt RJ: IgA nephropathy and Henoch-Schönlein purpura nephritis. Curr Opin Pediatr 2008;20:163-170.

10 Sunderkötter C, Roth J, Bonsmann G: Leukozytoklastische Vaskulitis. Hautarzt 2004; 55:759-785.

11 Gedalia A: Henoch-Schönlein purpura. Curr Rheumatol Rep 2004;6:195-202.

12 Fridey JL, Kaplan AA: Prescription and technique of therapeutic plasma exchange (review version 16.1). Jan 31, 2008. www. uptodate.com.
13 Smith JW, Weinstein R, AABB Hemapheresis Committee KL, AABB Hemapheresis Committee, American Society for Apheresis: Therapeutic apheresis: a summary of current indication categories endorsed by the $\mathrm{AABB}$ and the American Society for Apheresis. Transfusion 2003;43:820-822.

14 Eming R, Hertl M: Immunoadsorption in pemphigus. Autoimmunity 2006;39:609616.

15 Chen TC, Chung FR, Lee CH, Huang SC, Chen JB, Hsu KT: Successful treatment of crescentic glomerulonephritis associated with adult-onset Henoch-Schoenlein purpura by double-filtration plasmapheresis. Clin Nephrol 2004;61:213-216.

16 Chen CL, Chiou YH, Wu CY, Lai PH, Chung HM: Cerebral vasculitis in Henoch-Schönlein purpura: a case report with sequential magnetic resonance imaging changes and treated with plasmapheresis alone. Pediatr Nephrol 2000;15:276-278.

17 Kauffmann RH, Houwert DA: Plasmapheresis in rapidly progressive Henoch-Schoenlein glomerulonephritis and the effect on circulating IgA immune complexes. Clin Nephrol 1981;16:155-160.

18 Gaskell H, Searle M, Dathan JR: HenochSchönlein purpura with severe ileal involvement responding to plasmapheresis. Int J Artif Organs 1985;8:163-164.

19 Rech J, Fuchs F, Kallert S, Hueber AJ, Requadt C, Manger B, Kalden JR, Amann K, Strauss $\mathrm{R}$, Schulze-Koops H: Plasmapheresis therapy in an elderly patient with rapidly progressive Henoch-Schönlein purpura with disseminated organ involvement. Clin Rheumatol 2007:26:112-114
20 Lee J, Clayton F, Shihab F, Goldfarb-Rumyantzev A: Successful treatment of recurrent Henoch-Schönlein purpura in a renal allograft with plasmapheresis. Am J Transplant 2008;8:228-231.

21 Wortmann SB, Fiselier TJW, Van de Kar NCAJ, Aarts RAHM, Warris A, Draaisma JMT: Refractory severe intestinal vasculitis due to Henoch-Schönlein purpura: successful treatment with plasmapheresis. Acta Paediatr 2006;95:622-623.

22 Wen YK, Yang Y, Chang CC: Cerebral vasculitis and intracerebral hemorrhage in Henoch-Schönlein purpura treated with plasmapheresis. Pediatr Nephrol 2005;20: 223-225.

23 Shenoy M, Ognjanovic MV, Coulthard MG: Treating severe Henoch-Schönlein and IgA nephritis with plasmapheresis alone. Pediatr Nephrol 2007;22:1167-1171.

24 Hattori M, Ito K, Konomoto T, Kawaguchi $\mathrm{H}$, Yoshioka T, Khono M: Plasmapheresis as the sole therapy for rapidly progressive $\mathrm{He}$ noch-Schönlein purpura nephritis in children. Am J Kidney Dis 1999;33:427-433. 